
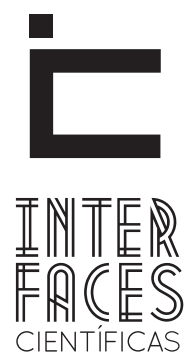

EDUCAÇÃO

ISSN IMPRESSO 2316-333X

ISSN ELETRÔNICO 2316-3828

DOI 10.17564/2316-3828.2015v4n1p35-46

\title{
MEMÓRIA[S] DO PROCESSO DE EXPANSÃO DE UMA INSTITUIÇÃO ESCOLAR: ESCOLA TÉCNICA FEDERAL DA BAHIA - UNIDADE DE ENSINO DESCENTRALIZADA DE VITÓRIA DA CONQUISTA
}

Gilneide de Oliveira Padre Lima ${ }^{1}$

Lívia Diana Rocha Magalhães ${ }^{3}$
Camila Nunes Duarte Silveira ${ }^{2}$

\section{RESUMO}

Após completar cem anos de Educação Profissional, em 2009, as escolas da rede federal brasileira passaram por reformulações na sua estrutura: de Escola de Aprendizes e Artífices até os atuais Institutos Federais de Educação, Ciência e Tecnologia. Dentro dessas transformações, nasceu a Unidade de Ensino Descentralizada (UNED) de Vitória da Conquista BA, na década de 1990. Esta pesquisa objetivou estudar o movimento de implantação dessa instituição escolar, observando o seu contexto sócio-histórico e econômico e as múltiplas relações que ali ocorreram. Analisamos o processo de expansão da Escola Técnica Federal da Bahia, destacando os antecedentes, a implantação propriamente dita e os primeiros anos de funcionamento da Unidade Descentralizada de Ensi- no de Vitória da Conquista, por meio das memórias construídas pelo seu grupo de fundadores. Concluímos que ao longo do processo de instituição da escola, foram constituídas memórias pessoais e coletivas em conformidade com os lugares que os sujeitos ocupam, configurando assim, a história e memória social da UNED de Vitória da Conquista, o que evidencia a relação dialógica existente entre elas.

\section{PALAVRAS-CHAVE}

UNED Vitória da Conquista. Instituição Escolar. Educação Profissional. Memória Coletiva. 


\section{ABSTRACT}

After completing hundred years of professional education in 2009 schools of the Brazilian federal system underwent reformulations in its structure: the School for Craftsmen and to the present Federal Institutes of Education, Science and Technology. Within these changes, was born Decentralized Teaching Unit (UNED) of Vitoria da Conquista - BA, in the 1990s. This research aimed to study the deployment movement of this educational institution observing their socio-economic and historical context and the multiple relationships that took place there. We have analyzed the process of expansion of the Bahia Federal Technical School, highlighting the background, the implementation itself and the first years of operation of the

\section{RESUMEN}

Después de completar cien años de la educación profesional en 2009 escuelas del sistema federal brasileño se sometió a reformulaciones en su estructura: la Escuela de Artesanos y de las actuales Institutos Federales de Educación, Ciencia y Tecnología. Dentro de estos cambios, nació Descentralizado Unidad Docente (UNED) de Vitoria da Conquista - BA, en la década de 1990. Esta investigación tuvo como objetivo estudiar el movimiento de despliegue de esta institución educativa observando su contexto socio-económico e histórico y las múltiples relaciones que tuvieron lugar allí. Hemos analizado el proceso de ampliación de la Escuela Técnica Federal de Bahía, destacando el fondo, la propia aplicación y los primeros años de funcionamiento de la Unidad Descentralizada de Vito-
Decentralized Unit of Vitoria da Conquista Education, through the memories built by its founders group. We conclude that throughout the school institution to process personal and collective memories were formed in accordance with the places that subjects occupy, so setting, history and social memory of Vitoria da Conquista UNED, which highlights the existing dialogical relationship between them.

\section{KEYWORDS}

UNED Vitória da Conquista. School Institution. Professional Education. Collective Memory. ria da Conquista Educación, a través de las memorias construidas por su grupo de fundadores. Llegamos a la conclusión de que toda la institución escolar para procesar los recuerdos personales y colectivas fueron constituidas de conformidad con los lugares que ocupan los sujetos, por lo ajuste, la historia y la memoria social de Vitoria da Conquista UNED, que pone de relieve la relación dialógica que existe entre ellos.

\section{PALABRAS CLAVE}

UNED Vitória da Conquista. Institución Escolar. Educación Profesional. Memoria Colectiva. 


\section{INTRODUCÃO}

As pesquisas relacionadas às instituições escolares são mais proeminentes no Brasil, sobretudo a partir dos anos de 1990. No âmbito da História da Educação, este tema tem importante relevância entre os educadores e constitui objeto de pesquisa em distintos Programas de Pós-Graduação em Educação no país. Para, além disso, juntos a esses programas tem-se ainda os grupos de pesquisas que se debruçam sobre a temática².

Entretanto é possível verificar que, nesses trabaIhos, ainda há poucas referências a noção de memória coletiva e social que povoam a escola e sua institucionalização oficial e real. Não verificamos uma discussão explícita sobre a memória coletiva dos grupos ou dos indivíduos que ocupam o espaço institucional escolar entre as categorias analíticas abordadas. Isto nos leva a crer que existem lacunas no estudo da memória enquanto categoria analítica nas pesquisas sobre as instituições escolares que perduram no tempo.

Consideramos que pesquisar instituições escolares, pressupõe pesquisar os grupos que a compõem direta ou indiretamente, gerando coexistências de memórias consensuais e memórias conflitivas, entre outros aspectos. Assim, neste artigo, tomamos o pensamento halbwachiano ${ }^{3}$ como um importante referen-

\footnotetext{
2. Dentre os quais é possível mencionar o Grupo do PPGE da Universidade Federal de Uberlândia (UFU), o PPGE da Universidade Federal de São Carlos (UFSCAR); a Universidade Nove de Julho (UNINOVE- SP); o mestrado da Universidade de Sorocaba (UNISO); o grupo de Histórias das Ideias e Instituições Educacionais vinculado à PUC-RJ e, ainda, o HISTEDBR com sede na UNICAMP que incorporou recentemente esta temática aos seus estudos. Além desses, também os grupos de estudos do Museu Pedagógico da Universidade Estadual do Sudoeste da Bahia - UESB e o PPG de Memória: Linguagem e Sociedade a ele correlato têm apresentado estudos relacionados às instituições escolares na região centro-sul da Bahia e sua relação com as teorias da memória. Estudos que tem possibilitando a nossa discussão de pesquisa.

3. Maurice Halbwachs (1877-1945), sociólogo durkeimiano a quem se atribui o mérito de transportar a teoria da memória do domínio individual para o campo coletivo/social. A sua maior contribuição foi à percepção de que, para além do âmbito da mera rememoração, existe a memória como fato social. Em sua obra póstuma "A memória coletiva" Halbwachs apresenta uma valiosa colaboração para os estudos da memória social.
}

cial para os estudos da memória coletiva que movimenta o interior das instituições escolares.

0 presente estudo versa a respeito do Instituto Federal de Educação Ciência e Tecnologia da Bahia (IFBA) que atravessa do século XX ao século XXI, passando por diferentes transformações: de Escola de Aprendizes e Artífices da Bahia, a Liceu de Artes e Ofícios da Bahia, daí a Escola Técnica Federal de Salvador, que se transforma em Escola Técnica Federal da Bahia, depois a Centro Federal de Educação Tecnológica da Bahia e, mais recentemente, a Instituto Federal de Educação, Ciência e Tecnologia da Bahia.

Particularmente tratamos da Unidade de Ensino Descentralizada (UNED) de Vitória da Conquista, uma escola criada no final da década de 1980, dentro da política de expansão da rede federal de educação profissional adotada pelo governo José Sarney; que juntamente com outras três UNEDs e a Unidade Sede (antiga Escola Técnica Federal da Bahia - ETFBA) passam a constituir o Centro Federal de Educação Tecnológica da Bahia (CEFET-BA), na década de 1990.

Com a sua trajetória marcada por mudanças e transformações que implicam em rupturas e permanências, as escolas de formação para o trabalho da rede federal vão construindo uma memória coletiva daqueles que ocupam o espaço institucional. Todas as mudanças ocorridas nessas escolas e também no campo educacional como um todo estão diretamente relacionadas às transformações sofridas no contexto social mais amplo, atendendo certamente aos interesses do capital. Pois assim como Nascimento (2009, p. 228) compreendemos que "a escola pública e o tipo de aprendizado oferecido no interior da mesma são entendidos como construção humana e social, fruto do processo histórico, buscando responder aos interesses da sociedade dominante".

Amparadas pela urgência em suprir de mão de obra capacitada, para a recém-inaugurada era industrial bra- 
sileira, as dezenove Escolas de Aprendizes e Artífices, criadas em 1909, passaram por transformações a fim de atender às novas demandas da sociedade. Inicialmente idealizadas para oferecer ensino profissional primário gratuito "aos filhos dos desfavorecidos da fortuna"; tinham como finalidade a formação de "operários e contramestres, ministrando-se o ensino prático e os conhecimentos technicos necessários aos menores que pretendem aprender um officio" (BRASIL, 1909).

Assim, tais escolas foram se transformando e se adequando para o atendimento das demandas sociais. Ao longo de sua história mudaram os seus destinatários, os métodos, as concepções e princípios que a norteiam, bem como os seus prédios, as oficinas, a forma de ingresso de servidores e discentes, a forma de escolha dos seus diretores, a legislação à qual está submetida, entre outros.

Ao revermos o percurso histórico mutativo dessas instituições escolares, identificamos um período de crescimento, na década de 1970, precisamente em 1978, quando houve a expansão do raio de atuação das escolas técnicas federais, por meio da transformação dessas escolas em CEFETs; coincidindo com o período de governo ditatorial que também se constituiu em um período de instabilidade econômica e de busca de reestruturação para a sustentação do regime. Constatamos que desde 1942 até aquele momento, o número de escolas permanece o mesmo - 23 escolas. Entretanto, em 1978, três delas foram transformadas em CEFETs: a Escola do Paraná, do Rio de Janeiro e a de Minas Gerais, ampliando o seu raio de atuação e passando a oferecer, além dos cursos de nível médio, já oferecidos, também o ensino de terceiro grau (graduação e pós-graduação).

Inspirados nos princípios que norteou a reforma universitária de 1968, a criação desses CEFETs, que passaram a funcionar em 1969, quando foi franqueada às Escolas Técnicas Federais do Rio de Janeiro, Minas Gerais e Paraná a instalação dos cursos de curta duração de engenharia de operação, buscava assegurar não só a diversificação do ensino superior, por meio da oferta de cursos de curta duração; mas também a ampliação da oferta de vagas nesse nível de ensino. Todo esse processo desenvolveu-se até o final da década de 1990 e foi permeado de impasses, conflitos e contradições.

Com início em 1978, o processo de "cefetização" das escolas técnicas federais do Paraná, Rio de Janeiro e Minas Gerais despertaram nas demais escolas da rede federal do território nacional o interesse em "cefetizar-se", ou seja, incorporar o ensino superior. Desse modo, a discussão sobre a "cefetização" das escolas técnicas federais alcançou a década de 1980 e 1990, resultando em debates veementes e em disputas político-regionais. Assim, estados e municípios passaram a solicitar a criação de novas unidades escolares, ou a transformação das suas Escolas Técnicas Federais em CEFETs, possivelmente considerando que a instalação desse centro representaria ou daria visibilidade política a sua região e município, ou ainda o reconhecimento da sua potencialidade e desenvolvimento social e econômico 5 .

Uma nova expansão das escolas técnicas federais ocorreu na década de 1980 quando o governo brasileiro contraiu, em 1986, junto ao Banco Mundial, um empréstimo para a implementação do Programa de Expansão e Melhoria do Ensino Técnico (PROTEC). 0 programa pretendia a instalação de 200 escolas técnicas industriais e agrícolas de $1^{\circ}$ e $2^{\circ}$ graus em cidades do interior do país, haja vista já existirem nas capitais as Escolas Técnicas Federais. O PROTEC, de acordo com o Ministério da Educação e Cultura/Secretaria de Ensino de Segundo Grau (MEC/SESG - 1990) estaria amparado nos princípios de descentralização, participação, regionalização, interiorização e gratuidade.

O PROTEC foi alvo de muitas críticas de educadores e estudiosos no âmbito do Trabalho e Educação.

4. Denominação atribuída à transformação das Escolas Técnicas Federais em Centros Federais de Educação Tecnológica (CEFET)

5. Sobre o processo de "cefetização" das escolas técnicas federais (LIMA, 2014, p. 64-75). 
Para Cunha (2009), houve forte presença, no Governo Sarney, de acordos, alianças e manobras políticas realizadas em função de interesses político-partidários que viabilizaram a eleição do Presidente Tancredo Neves. As ações do Ministério da Educação, nesse governo, de modo geral, estiveram voltadas principalmente, em pactuar alianças e sedimentar apoio dos diferentes grupos políticos.

Segundo Ciavatta (2007, p. 17) a notícia governamental da construção de duzentas escolas técnicas e agrotécnicas, no início de 1986, foi polêmica entre os educadores, que se questionavam: por que essa expansão do ensino técnico quando havia grande carência de ensino de $2^{\circ}$ grau no país? Também era questionada a concepção de educação profissional utilitarista, tecnicista e produtivista que sustentava o programa.

Apesar das críticas, O PROTEC se constituiu num elemento chave no Ministério da Educação no governo Sarney, pois esse programa alavancou a expansão da rede federal de educação profissionalizante de $1^{\circ}$ e $2^{\circ}$ graus e a criação das Unidades de Ensino Descentralizadas (UNEDs); entre elas a expansão da Escola Técnica Federal da Bahia (ETFBA), ao final da década de 1980.

A expansão da ETFBA se deu tanto pela ampliação do número de unidades escolares com a criação e implantação de quatro Unidades de Ensino Descentralizadas no interior do estado como pela ampliação do nível de atuação, quando em 1993, essa escola foi transformada em CEFET-BA e passou, então, à condição de ofertar, além do ensino de nível médio, o ensino de nível superior.

É importante salientar que, desde $1909^{6}$, quando foi criada por Nilo Peçanha, a Escola de Aprendizes e Artífice da Bahia, até o ano de 1994, portanto durante 85 anos, a Bahia teve apenas uma escola técnica federal. Os recursos do PROTEC garantiram uma expansão do número de unidades escolares federais iné-

6. A Escola de aprendizes e Artífices da Bahia foi instalada em 2 de julho de 1910. ditas na Bahia. Ligadas à ETFBA foram implantadas UNEDs em Barreiras, Vitória da Conquista, Valença e Eunápolis; além de outras três escolas agrotécnicas em Santa Inês, Guanambi e Senhor do Bonfim. Apesar dos critérios anunciados como requisitos para as cidades nas quais seriam implantadas as unidades de ensino houve grande disputa entre os poderes regionais e o destino das escolas do PROTEC dependeu das correlações políticas de interesse regional.

As UNEDs são escolas técnicas federais, criadas a partir do PROTEC, situadas em cidades do interior e vinculadas a uma Escola-mãe, que é a Escola Técnica Federal existente no estado federativo onde se encontra a UNED. No caso da Bahia, como ressaltamos, as UNEDs são vinculadas à ETFBA, com sede em Salvador. A UNED de Vitória da Conquista foi criada por meio da Portaria Ministerial 1.718, 15 de dezembro de 1994 e contou com recursos do PROTEC para a sua construção.

Atendendo ao que preconizava o programa, foi celebrado um convênio entre a Prefeitura Municipal de Vitória da Conquista (PMVC), ETFBA e o MEC. O objeto do convênio era o repasse de recursos financeiros ao município pela SESG para a construção do prédio em terreno doado pela prefeitura com institucionalização e administração da ETFBA.

A construção da escola, prevista para ser concluída em seis meses, durou mais de cinco anos. Nesse ínterim, as fontes consultadas apontam para a existência de disputas políticas entre as lideranças regionais desde o âmbito municipal até o federal. Também revelaram todo um movimento adotado pela administração municipal no sentido de concretizar a construção e viabilizar o funcionamento da instituição. Fazendo com que a escola deixasse de ser pensada apenas como um lugar de produção/reprodução do conhecimento e passasse a ser atribuidora de prestígio político aos detentores do poder local.

Com os recursos para construção assegurados pelo programa, as dificuldades para a implantação da es- 
cola vieram à tona, logo após a sua inauguração. Dificuldades de toda ordem se fizeram presentes: desde material de consumo até falta de recursos humanos para o funcionamento da unidade escolar. Contudo, segundo os depoimentos coletados na pesquisa, também existiram forças propulsoras que impulsionaram o desenvolvimento da escola. Tais forças, notadamente, estavam relacionadas ao entusiasmo presente entre o grupo aqui denominado de instituidores. As entrevistas revelam a existência de um clima contagiante presente entre gestores, professores, técnicos administrativos e alunos, comprometidos em fazer a escola funcionar e funcionar bem, garantindo a qualidade educacional inerente às escolas congêneres em todo o país.

Frente a isso, poderíamos dizer que, ao longo do processo de instituição da escola, se formaram memórias pessoais e coletivas constituídas em conformidade com os lugares ocupados pelos sujeitos, de acordo com a sua localização regional, configurando assim, a história e memória social da UNED de Vitória da Conquista, evidenciando desse modo, a relação dialógica existente entre memória coletiva e memória social?

O processo de constituição da história da ETFBA, particularmente da UNED de Vitória da Conquista, como em outras instituições, é carregado de certas singularidades sentidos e significados, de disputas políticas, do ponto de vista sobre suas necessidades educacionais, regionais e sociais. Isso porque, no interior de cada instituição escolar estão sujeitos que vivenciam a realidade concreta.

É importante lembrar que, as memórias coletivas e sociais evidenciam individualidades e entrecruzamentos, ou seja, ora é o sujeito que fala do lugar dele, é a sua memória individual que fala, embora seja como diria Halbwachs (2006, p 14), a partir de uma visão de mundo, de uma memória social, isto é, uma memória coletiva que retoma as experiências e vivências comuns.

7. Sobre a relação dialógica entre memória coletiva e memória social (MAGALHÃES, SOUZA e SANTOS, 2009).
Nessa perspectiva, no desenvolvimento da nossa investigação, lançamos mão de fontes orais, escritas e iconográficas e tomamos como recurso analítico a teoria da memória aportada por Maurice Halbwachs (2006, p. 14), particularmente seus conceitos a respeito da memória coletiva, memória individual, memória autobiográfica, tempo e espaço; buscando a sua articulação com os discursos produzidos e producentes pelos atores, protagonistas e coadjuvantes, que experienciaram o percurso histórico descrito pela UNED de Vitória da Conquista desde a sua concepção até os seus primeiros anos de funcionamento.

Naturalmente que nesse processo há muitas memórias construídas pelos trabalhadores e estudantes que vivenciaram e erigiram o dia a dia da instituição, mas também daqueles interlocutores que conduziram o movimento de criação e implantação da escola, facultaram a discussão e instalação das novas escolas: lideranças políticas nacionais e regionais que, seja no ministério da Educação, na Prefeitura Municipal de Vitória da Conquista ou na Câmara de Vereadores do Município, deram a sua contribuição para a instalação dessa escola na referida cidade. Foi importante perceber quais as memórias que estavam constituídas dentro e ao redor desse espaço. Para tanto, tornou-se imprescindível entrevistar esses sujeitos que estiveram presentes nesse processo, os quais denominamos "grupos fundadores" da escola.

Dentro desse “grupo de fundadores”, trabalhamos, didaticamente, com dois subgrupos. Chamamos de "Grupo constituidores", aqueles que acompanharam a implementação da escola como representantes oficias ou designados por estes e "Grupo dos instituidores" aqueles outros gestores, professores e alunos que vivenciaram o cotidiano do processo de instituição do IFBA. Isto sem desconsiderar que no caso da gestão da escola, há um movimento de interação no desenvolvimento da vida escolar, uma vez que os gestores são professores e a secretaria sempre vinculada a essas administrações. 
Rastreamos e analisamos discursos produzidos e producentes sobre o percurso dessa escola, como também documentos escritos e iconográficos que atestam sua instalação e implementação.

Nos depoimentos do grupo dos instituidores, há um consenso sobre as dificuldades materiais da escola. Porém, para todos eles, a escola é tida como um espaço diferenciado, de qualidade e os problemas no cotidiano escolar são imediatamente apresentados em comum com as soluções encontradas para fazê-la funcionar. Para esse grupo, ao mesmo tempo em que a escola é uma conquista, também é uma dádiva e carece de "ajuda" e do reconhecimento de todos. Passa a ser um presente, a ser cuidado.

É importante ressaltar que parte dos indivíduos do grupo de constituidores é formada por colegas de escola, correligionários políticos e apresentam vivências comuns de parte da sua vida: ou a infância e juventude passada na cidade de Vitória da Conquista das décadas de 1940-1950, ou, mais tarde, quando comungavam dos mesmos ideais políticos que os uniram em torno de uma mesma ideologia no campo político partidário. Hoje são pessoas com idade variável entre 70 e 92 anos e não mais participam dos grupos políticos de outrora, estão aposentados, mas mantém esses vínculos.

Como ressalta Halbwachs (2006, p. 10), a dinâmica de participação dos indivíduos nos grupos é decisiva para a rememoração do passado. As suas narrativas revelam memórias de um grupo que compartilha, de algum modo, de uma visão política comum, de que o cargo público, deve responder pelos interesses da comunidade, região da qual se origina seu representante. Esse "grupo" se remete ao processo político de instalação e inauguração da escola, fundamentando-se na conquista política do grupo, principalmente por meio de um de seus membros.

O sentimento de pertencimento a um grupo social específico é muito forte na maior parte do grupo dos instituidores. Naturalmente, dentro desse grupo há muitas memórias comuns, memórias diferentes, mas comuns. Também existem memórias que são próprias de cada função exercida pelos indivíduos no espaço institucional. Notadamente, as memórias dos gestores e administradores estão mais voltadas para acontecimentos ligados à gestão, enquanto que professores e alunos têm memórias muito mais ligadas ao processo de ensino-aprendizagem.

As memórias se diferenciam na medida em que cada um vivencia as experiências do seu lugar que sempre será diferente dos demais em virtude dos quadros sociais da memória de cada sujeito. A motivação de todos, a integração entre os membros do grupo e o empenho nos parece uma lembrança comum a todos os atores desse processo.

Assim como no "grupo dos constituidores", também, há um movimento muito dinâmico entre o "grupo dos instituidores" da escola. Todos os entrevistados que eram gestores no momento da implantação da UNED, hoje são professores, isto é, não estão mais em exercício de cargo de gestão, apenas um deles continua residindo e trabalhando em Vitória da Conquista. Uma professora se aposentou e passou a residir em outro estado; um estudante, hoje é servidor técnico administrativo da escola. 0 professor que, ao iniciar as suas atividades, não era gestor, atualmente é.

Evidentemente, que a memória de cada sujeito, mesmo aqueles que permanecem nas mesmas funções, muda em virtude das novas informações e experiências por ele acumuladas. A vivência do passado é mesclada com a visão que cada um tem do presente. 0 passado é recomposto a partir do presente.

A necessidade de situar uma lembrança no espaço também é verificada nas entrevistas. Um dos entrevistados, por exemplo, ao falar do lançamento da Pedra Fundamental para a construção da escola primeiro descreve o terreno preparado para tal solenidade. Em sua narrativa ele parece visualizar os lugares, primeiro o ônibus, lotado de autoridades municipais, depois 
a área limpa, terraplanada e preparada para o evento. Lembrança que também está presente na fala de um dos professores entrevistados que, ao contar sobre a sua participação no concurso público, por exemplo, para o seu ingresso na escola, narra com riqueza de detalhes a sala onde a prova aconteceu.

Para Halbwachs (2006) o ambiente material traz a marca do seu grupo, assim como cada grupo está impregnado das marcas do seu espaço. Destarte, o espaço se constitui numa condição essencial de existência dos grupos sobre o qual o autor assegura:

O espaço é uma realidade que dura: nossas impressões se sucedem umas às outras, nada permanece em nosso espírito e não compreenderíamos que seja possível retomar o passado se ele não estivesse conservado no ambiente material que nos circunda. (HALBWACHS, 2006, p. 170)

As referências ao tempo cronológico são bastante reveladoras. Não há, nas narrativas, referências às datas específicas, mas as lembranças são narradas em forma de blocos temporais referentes a acontecimentos pessoais e políticos: antes ou depois de algum acontecimento mais marcante. "O ano em que eu me aposentei”, diz um dos entrevistados; "foi durante a gestão de fulano", ou "depois de promulgada à constituinte”, são recorrências comuns para situar a lembrança no tempo. Também, ouvimos dos entrevistados referências marcadas por acontecimentos de cunho pessoal, como "eu estava grávida da minha segunda filha”, ou "eu ainda não havia trazido a minha família para cá”.

Halbwahcs (2006, p. 106) destaca que “toda memória coletiva tem como suporte um grupo limitado no tempo e no espaço". Entretanto na sua concepção, embora uma representação coletiva do tempo seja necessária e indispensável para organização da vida em sociedade, essas divisões não são universais, ou seja, as divisões do tempo têm significados diferentes para cada grupo social: "não há um tempo universal e único, mas a sociedade se decompõe em uma multiplicidade de grupos, cada um com sua própria duração" (HALBWAHCS, 2006, p. 153).
Para ele, os quadros da memória coletiva não nos conduzem a datas exatas, isso porque essa memória é uma corrente de pensamento contínuo que só retém do passado aquilo que está vivo na consciência individual ou do grupo. Nessa continuidade não há linhas de separação claramente traçadas, mas limites irregulares e incertos. Sem nos lembrarmos de um dia, podemos recordar um período. À medida que se distanciam os acontecimentos são recordados sob a forma de conjuntos.

Ainda é importante observar que muitas vezes as narrativas vão buscar no discurso dados ou fatos comprovados para apoiar seu relato. Um dos gestores entrevistados, por exemplo, após ter aceitado participar da entrevista, por e-mail, nos respondeu: "Anotei as suas dúvidas e vou buscar as informações, pois já se passaram alguns anos e tenho que ser fiel aos fatos". Outros disseram, "espera um pouco porque eu preciso me preparar". Por mais que fosse explicitado ao participante que o nosso interesse estava voltado para sua memória, ou seja, o que ele guardou do acontecimento. Esse fato nos faz acreditar que, em muitos momentos, memória autobiográfica e memória histórica se entrecruzam de tal forma que quase se tornam inseparáveis ${ }^{8}$.

As entrevistas realizadas com o grupo dos instituidores foram permeadas de muita emoção. Houve quem, num determinado momento, se desmanchasse em lágrimas. Uma professora se diz saudosa: “a coisa marcante que deixa esse saudosismo, era o entrosamento entre os professores". Após um momento de forte emoção, um dos gestores respira fundo e diz: “isso mexe muito com a gente, mexe muito". Enquanto outro enaltece a vontade, dedicação e amor despendidos pelos pioneiros daquela instituição escolar.

Por outro lado, também comparecem ressentimentos, ou vividos no passado com permanências nos dias atuais, ou vividos na atualidade. Há depoimentos ressentidos da falta de reconhecimento, materializado

8. Para uma discussão sobre o par conceitual Memória Histórica e Memória autobiográfica em Halbwachs (LIMA, 2014, p. 96-97). 
pela ausência de apoio a algum projeto. Há quem se ressente de, apesar de exercer a função, não ter sido designada para ocupação de um cargo de direção. Há ainda quem sente falta de reconhecimento na atualidade por todo o trabalho que já prestou à instituição por mais de quarenta anos de vida.

Como podemos observar, ainda que seja fortemente marcada pela memória social, a memória individual também é presente nos discursos. Isso porque, as memórias individuais estão dentro do grupo, mas, guardam singularidades. Essa memória, também, aparece com os indivíduos do grupo das lideranças políticas. Existe quem, embora se relacionasse politicamente com o grupo que conviveu, traz a memória de que ele tenha sido o sujeito central do processo.

Cada um a seu modo, pensa ser o sujeito central em algum momento do processo, seja por ter encaminhado a burocracia, seja por ter realizado os encaminhamentos políticos ou burocráticos. A partir de uma referência social, que é o grupo, a memória individual guarda certa singularidade. 0 que nos leva a considerar que a memória autobiográfica, também, comparece nos discursos produzidos, compreendendo memória autobiográfica sob o ponto de vista halbwachiano: "é a memória de nossa vida” (HALBWACHS, 2006, p. 73).

A pesquisa nos permitiu vislumbrar a existência de uma relação dialógica entre a memória coletiva e a memória social, uma vez que as memórias coletivas se relacionam com os diversos grupos sociais, que, por sua vez, integram as relações entre o todo e as partes na sociedade concreta, conforme assinalam Magalhães, Souza e Santos (2009, p. 107): “[...] toda memória é social, e a memória coletiva decorre das experiências vividas ou herdadas, recebidas por grupos sociais, se origina e é resultado de realidades construídas pela memória social”.

Analisando um pouco mais as memórias dos representantes políticos e do gestor do MEC, verificamos que os discursos desses sujeitos são portadores das representações que eles têm da sociedade e das suas necessidades. Eles entendem que a escola é um "importante equipamento educacional" para responder às demandas econômicas da região. Tanto para formar mão de obra qualificada para as indústrias ainda incipientes no município de Vitória da Conquista e região, quanto para oferecer oportunidades de trabalho assalariado para os egressos dessas instituições, muito possivelmente, jovens oriundos da classe trabalhadora.

Poderíamos dizer que encontramos nas entrevistas, entre os "dois grupos", memórias bastante distintas. Uma memória que se referencia a um quadro social baseado na ordem política, na importância política da escola para a comunidade local, ao fato de ser pertencente à mesma, assegurando a coesão do grupo e o sentimento de pertinência entre seus membros. E a outra, conferindo, portanto, uma inerente relação entre as memórias coletivas de professores, professores gestores e técnicos administrativos, como também alunos, vivenciada no dia a dia escolar.

Memórias estas que permeiam o cotidiano da instituição, revelando que pensar e fazer, a práxis, exige outras coerências que nem sempre são previstas no projeto de uma escola. Memória que se sedimenta na experiência compartilhada, construidora de memórias comuns em suas distinções de tornar a escola um lugar de saber e fazer educação, nada fácil, porém muito importante.

\section{REFERÊNCIAS}

BRASIL. Decreto $\mathbf{n}^{0}$ 1.606, de 29 de dezembro de 1906. Cria uma Secretaria de Estado com a denominação de Ministério dos Negócios da Agricultura, Indústria e Comércio.

BRASIL/MEC. Portaria n⿳0 $\mathbf{1 . 7 1 8 / 9 4}$. Autoriza o Centro Federal de Educação Tecnológica da Bahia a promover o funcionamento da Unidade de Ensino Descentralizada de Vitória da Conquista-BA. 
CIAVATTA, Maria. Memória e temporalidades do trabalho

e da educação. Rio de Janeiro: Lamparina; Faperj, 2007.

\section{CUNHA, Luiz Antonio. Educação, Estado e}

democracia no Brasil. 6.ed. São Paulo: Cortez; Niterói, RJ: Universidade Federal Fluminense; Brasília, DF: FLACSO do Brasil, 2009.

DUVIGNAUD, Jean. Prefácio. In: HALBWACHS, Maurice. A memória coletiva. Tradução de Beatriz Sidou. São Paulo: Centauro, 2006.

HALBWACHS, Maurice. A memória coletiva. Tradução de Beatriz Sidou. São Paulo: Centauro, 2006.

LIMA, Gilneide de O. Padre. Memória(s) do processo de expansão da Escola Técnica Federal da Bahia: a Unidade de Ensino Descentralizada de Vitória da
Conquista. Dissertação (Mestrado em Memória: Linguagem e Sociedade) - Universidade Estadual do Sudoeste da Bahia, Vitória da Conquista, 2014.

MAGALHÃES, Lívia Diana R.; SOUZA, Daniela Moura R. e SANTOS, Polliana Moreno dos. Memória e transmissão das experiências como desafios para os estudiosos da educação. Revista HISTEDBR [online], n.36, Campinas, dez 2009. p.105-114.

MEC/SESG. PROTEC: Criação, implantação e desenvolvimento, janeiro 1990.

NASCIMENTO, Maria Isabel Moura e NASCIMENTO, Manoel Nelito Matheus. A escola pública:

considerações a partir da divisão social do trabalho. Revista HISTEDBR [on-line], n.34, Campinas, jun 2009. p.223-233.

\begin{abstract}
1. Mestre em Memória: Linguagem e Sociedade da Universidade Estadual do Sudoeste da Bahia - UESB Campus Vitória da Conquista. Participante dos grupos de Pesquisa História, Trabalho e Educação e Memória geracional, Políticas Educacionais e Trajetórias Sociais ambos do Museu pedagógico da UESB. Professora do Instituto Federal Ciência e Tecnologia da Bahia - Campus de Vitória da Conquista. E-mail: gilneidepadre@hotmail.com 2. Doutoranda do Programa de Pós - Graduação em Memória: Linguagem e Sociedade da Universidade Estadual do Sudoeste da Bahia - UESB Campus Vitória da Conquista. Bolsista pela Fundação de Amparo à Pesquisa do Estado da Bahia - FAPESB, e participante dos grupos de Pesquisa Fundamentos em Memória, Religião, Imagem e Educação e Memória Geracional, Políticas Educacionais e Trajetórias Sociais. E-mail: mila-ped@hotmail.com 3. Professora da Universidade Estadual do Sudoeste da Bahia. Doutora em educação pela UNICAMP, com pós-doutorado em Psicologia Social pela UERJ e estágio na Universidad Complutense de Madri. Coordenadora Geral do Museu Pedagógico da UESB, do grupo de Pesquisa Memória Geracional, Políticas Educacionais e Trajetórias Sociais e do Programa de Pós-Graduação em Memória: Linguagem e Sociedade da UESB. E-mail: Irochamagalhaes@gmail.com
\end{abstract}

